\title{
La irrupción de lo queer: Cuerpos abyectos y eróticas disidentes en los márgenes del cine argentino contemporáneo ${ }^{1}$
}

\section{Romina Smiraglia}

Universidad de Buenos Aires

\begin{abstract}
"No queremos que nos persigan, ni que nos prendan, ni que nos discriminen, ni que nos maten, ni que nos curen, ni que nos analicen, ni que nos expliquen, ni que nos toleren, ni que nos comprendan: lo que queremos es que nos deseen".
\end{abstract}

Néstor Perlongher

\section{Resumen}

Desde la primera década del siglo XXI en la Argentina, y frente a la saturación de representaciones normativas del género y de la sexualidad dentro de la industria cultural, resulta significativo que el discurso cinematográfico haya producido imágenes alternativas respecto a los géneros, las sexualidades, los vínculos eróticos y amorosos, la familia. Este trabajo tiene como objetivo poner en relación este fenómeno con la discusión en torno al surgimiento de un Nuevo Cine Queer. Para ello se presenta una breve introducción a esta noción en relación con las representaciones en torno a los cuerpos intersex, utilizando como corpus de trabajo dos películas estrenadas recientemente en el país: XXY (Lucía Puenzo, 2007) y El último verano de la boyita (Julia Solomonoff, 2009).

Palabras clave: Nuevo Cine Queer; intersex; género; cuerpos; cine argentino contemporáneo

1 La hipótesis central en la que se apoya este trabajo, la irrupción de lo queer en el cine argentino contemporáneo, es parte de mi investigación doctoral y fue presentada por primera vez a través de la ponencia "Sexualidades dispares. Representaciones y construcciones de género en el Nuevo Cine Argentino" en junio del 2009, en el Primer Congreso Internacional de la Asociación Argentina de Estudios de Cine y Audiovisual. Asimismo, una versión anteriory más breve de este artículo fue presentada en agosto del 2013 en el Tercer Congreso Internacional Artes en Cruce "Los espacios de la memoria. Memorias del porvenir" (UBA, Argentina). 


\section{Abstract}

Facing a saturation of normative representations of gender and sexuality in the culture industry, the cinematographic discourse has managed, ever since the first decade of the XXI century in Argentina, to produce alternative images as regards genders, sexualities, erotic and affectionate bonds, family. This paper has the aim of setting the link between this phenomenon and the discussion on the emergence of the New Queer Cinema. For this purpose, a brief introduction is issued related to representations of intersex bodies thus presenting as corpus two films recently released in the country: XXY (Lucía Puenzo, 2007) y El último verano de la boyita (Julia Solomonoff, 2009).

Key words: New Queer Cinema; intersex; gender; bodies; contemporary Argentine cinema

El cuerpo -retomando la frase de Barbara Kruger- es un campo de batalla. Un espacio privilegiado de actuación de las técnicas de sujeción y/o normalización de las que emerge el sujeto. Pero también un espacio de resistencia, de contra-productividad (Haraway, Ciencia, cyborgs y mujeres; Preciado, Testo yonqui). Podríamos decir que más que tener un cuerpo o ser un cuerpo, nos convertimos en un cuerpo, ${ }^{2}$ el cual negociamos constantemente a través de normas sociales y condiciones de agencia- que nunca elegimos, y que no están bajo el total control consciente del sujeto, pero que al mismo tiempo "ocupamos, invertimos y resignificamos, puesto que la norma nunca logra determinarnos por completo" (Butler, Cuerpos que importan 186). En última instancia -como sugiere Butler- es una "práctica de improvisación en un escenario constrictivo" (Deshacer el género 13).

Desde este horizonte de sentido, el género, como la sexualidad, no pueden ser pensados como una propiedad de los cuerpos, como preexistentes o construidos de forma independiente de las normas reguladoras que gobiernan su materialización, sino que es el efecto de una dinámica del poder que produce - demarca, diferencia- los cuerpos que controla, abriendo(cerrando), de esta manera, las (im)posibilidades de determinadas representaciones de los mismos. Es por ello que existen algunas combinaciones entre cuerpo, género y sexualidad que son aceptadas en la sociedad, y otras que no. Las normas de género delimitan cómo y de qué forma podemos presentarnos en el espacio público, quién será protegido por la ley, qué vínculos van a ser reconocidos y cuáles no. ${ }^{3}$

2 Quisiera agradecer esta reflexión en torno al cuerpo a la Dra. Meri Torras, directora del grupo de investigación "Cuerpo y textualidad" con sede en la Universidad Autónoma de Barcelona; en el transcurso de un seminario dictado por Torras en esa universidad introdujo esta aproximación al cuerpo.

${ }^{3}$ En una conferencia dictada en el marco del seminario de doctorado "Performatividad, género y teoría social: la revisión de la categoría del sujeto" en la Facultad de Ciencias Sociales de la Universidad de Buenos Aires (UBA) en el 2009, Judith Butler, al analizar la noción de performatividad, se explayó sobre este punto. Tomo esta reflexión de esa conferencia. 
En relación con lo anterior, el cine —como práctica significante- produce efectos, y lejos de ser mímesis de la realidad, es en sí un medio poderoso de movilización y expresión del imaginario socio-sexual (Colaizzi, Género y representación). Tiene el poder de (des)legitimar determinados discursos, sujetos, valores y, al igual que los discursos institucionales, funciona como una tecnología social que al nombrar, representar y/o definir la feminidad o la masculinidad también las están creando. No obstante, aún frente a las tecnologías sociales que se encuentran operando sobre la construcción del género, tecnologías de género que producen o promueven representaciones del mismo, los términos de una construcción diferente subsisten en los márgenes de los discursos hegemónicos (de Lauretis, Technologies of Gender). Esos espacios son, como señala de Lauretis retomando a Foucault, los puntos ciegos, el fuera de plano, de los aparatos del poder-saber, aquí y ahora.

En el marco de lo que la crítica ha denominado el Nuevo Cine Argentino (Aguilar; Amado; Peña), dos películas estrenadas recientemente - XXY (Lucía Puenzo, 2007) y El último verano de la boyita (Julia Solomonoff, 2009) - ponen el foco en la intersexualidad, disputando, así, el monopolio que sobre la representación de los cuerpos intersex detenta el discurso médico. En ese sentido, este trabajo tiene como objetivo recorrer los distintos procedimientos figurativos y/o narrativos de estas propuestas que contribuyen al desafío de producir otra mirada, de construir las condiciones para la representación de otros sujetos de la mirada. ${ }^{4}$

\section{Nuevo Cine Argentino, ¿Nuevo Cine Queer?}

En estos últimos años, y en simultáneo a una aparente flexibilización en la mirada pública sobre los modelos de género y sexuales hegemónicos, sexualidades dispares, cuerpos abyectos y vínculos no convencionales se filtran en las pantallas cada vez con más fuerza. Irrumpen textos fílmicos a contracorriente que problematizan la premisa hegemónica: "un individuo $=$ un cuerpo $=$ un sexo $=$ un género = una sexualidad" (Preciado, Testo yonqui 90). Ruby Rich ha bautizado a este fenómeno como "Nuevo Cine Queer": un amplio grupo de películas que surgen desde los noventa, que más que compartir una estética, o una estrategia narrativa en común, comparten una actitud: "son irreverentes" (18). Michele Aaron, en sintonía con la lectura propuesta por Rich, las denomina desafiantes, por compartir en principio las siguientes características: en primer lugar, estos films le dan voz a Ixs marginadxs, no solo por poner el foco en la comunidad homosexual o lesbiana, sino especialmente en los subgrupos dentro de la misma, como la exploración sobre la experiencia gay en afroamericanos. Por otro lado, su preocupación principal ya no sería convertir los estereotipos negativos en torno al género y las sexualidades no heteronormativas en imágenes positivas. Los

${ }^{4}$ Desafío al que llama Teresa de Lauretis. Para un mayor desarrollo de este punto, véase su artículo "Rethinking Women's Cinema" en Figures of Resistance. Essays in Feminist Theory. Ed. Patricia White. Urbana-Chicago, U of Illinois P, 2007. 25-47. 
personajes que transitan por estos films no piden comprensión, no buscan establecer ejemplos a seguir, ni piden disculpas por lo que (no) son. ${ }^{5}$

En sus inicios, la palabra queer equivalía a un insulto para denominar aquello que no encajaba, que estaba incompleto, o bien resultaba excesivo; en pocas palabras, lo ambiguo, lo indefinido dentro del entramado social. El término no tenía un contenido específico, sino más bien —en palabras de Preciado- "pretendía reunir todas las señas de lo abyecto" ("Queer: historia de una palabra" 16). Lo abyecto ${ }^{6}$ —en los términos que propone Julia Kristeva - como "aquello que perturba una identidad, un sistema, un orden. Aquello que no respeta los límites, los lugares, las reglas" (11). Será recién en los setenta cuando el insulto queer pase a ser reapropiado y resignificado por sus víctimas como forma de resistencia política. Generalmente, la palabra se asocia con la comunidad LGBT, como un paraguas que abriga todas las identidades no heteronormativas. Sin embargo, el término en su utilización contemporánea implica una revisión crítica de los procesos —sociales, políticos y culturales - a través de los cuales se construyen las nociones binarias de género y sexualidad hegemónicas (Aaron). Además, lo queer no solo desafía el paradigma heterosexual, sino que es una posición crítica frente a los mecanismos de naturalización y exclusión producto de la cristalización identitaria en general. Es por ello que la caracterización inicial propuesta por Aaron podría pensarse por fuera de la noción de "sub-grupos" dentro de las comunidades gais y lesbianas, y simplemente incluir diversas experiencias en tensión con la hetenorma: trabajadorxs sexuales, cuerpos transgénero, transexuales, intersex, entre otrxs.

Respecto a este punto es interesante señalar que en la reapropiación del término por parte de la comunidad hispanoparlante se pierde el choque "sonoro-visual" —por tratarse de un insulto-que se experimenta en el mundo anglosajón. En pocas palabras, utilizar la palabra queer, claramente, no tiene el mismo impacto que emplear "rarito", "maricón", "trola" o "torta". Por otro lado, y a pesar de que en los últimos años investigadores como Ruby Rich o Vinodh Venkatesh, entre otrxs, han comenzado a reflexionar sobre producciones audiovisuales latinoamericanas, lo cierto es que la noción de Nuevo Cine Queer nace mirando la cinematografía anglosajona y europea continental, y aún falta mucho camino por recorrer. En otras palabras, ¿qué sucede cuando estos marcos teóricos "viajan", cuando se enfrentan con otros productos culturales, en otros contextos distintos al que fueron pensados? En ese sentido es que se vuelve fundamental interrogarlos, y en ese proceso (re)formular estrategias para relacionarnos con nuestros objetos de estudio.

Retomando la noción de un Nuevo Cine Queer, frente a la saturación de representaciones normativas del género y de la sexualidad dentro de la industria cultural, resulta significativo que el discurso cinematográfico haya producido imágenes alternativas respecto a los géneros, las

${ }^{5}$ Michele Aaron arriesga otras posibles características en New Queer Cinema: A critical reader (3-14). En este artículo solo nos detendremos en las dos primeras.

${ }^{6}$ El término queer (de Lauretis; Butler; Preciado), la noción de abyecto (Kristeva) y se podría agregar la de monstruosidad (Braidotti; Haraway) ciertamente tienen múltiples filiaciones en común. Dicho esto, vale aclarar que los mismos no son equivalentes, ni mucho menos intercambiables. 
sexualidades, los vínculos eróticos y amorosos, la familia. En la Argentina, desde la primera década del siglo $\mathrm{XXI}$, surgen textos fílmicos cuyas estrategias enunciativas exponen relaciones que se diferencian, de algún modo, de las interpelaciones normativas en torno a la regulación y socialización de los cuerpos, enmarcados en el fenómeno que ha sido denominado por la crítica como Nuevo Cine Argentino: incesto, zoofilia, parricidio y demás perversiones en Animalada (Bizzio, 2000), Géminis (Carri, 2005) y El niño pez (Puenzo, 2009); eróticas disidentes en Un año sin amor (Berneri, 2005), Hoteles (Paparella, 2004) y Vagón Fumador (Chen, 2002); identidades sexuales ambiguas en Tan de repente (Lerman, 2003) y Plan B (Berger, 2010), la homosociabilidad por fuera del marco heteronormativo —también conocida como bromance- ${ }^{7}$ en Excursiones (Acuña, 2009); entre otros. Cada uno de estos films produce, a través de diferentes procedimientos figurativos y/o narrativos, fisuras en el sistema hegemónico de representaciones. No es que nunca hayan existido films con estas características, sino que la fuerte proliferación de los mismos en estos últimos años -y no solo en Argentina, como vengo sugiriendo- le plantea a la teoría cinematográfica y a los estudios de género de forma particular, la necesidad de una reflexión sobre los mismos.

Esta renovación en la cinematografía está en relación - no es su directo resultado- con importantes debates abiertos en el país sobre el género y la sexualidad. En las últimas décadas, y gracias la incansable lucha de movimientos de mujeres, feministas y de la diversidad sexual en alianza con otros actores socio-políticos en la sociedad, se "han discutido y aprobado diversas leyes nacionales sobre sexualidad, reproducción, familia y género", entre ellas podemos nombrar: la Ley 26.618, conocida como "matrimonio igualitario" y la Ley 26.743, sobre "identidad de género", las cuales han logrado transformar "marcos normativos sacralizados" (Hiller y Jones).

Producto de este giro queer presente en parte de la cinematografía argentina contemporánea, la intersexualidad se cuela en las pantallas. El cuerpo intersex es un cuerpo sexuado signado por la ambigüedad debido a su variación respecto al modelo femenino o masculino vigentes en la sociedad, y es justamente esta ambigüedad la que muchas veces condena esos cuerpos a distintas tecnologías - hormonales, quirúrgicas - de normalización (Maffia). Bajo la ansiedad cultural de definir lo que se ve para volverlo inteligible, se realizan exámenes hormonales, se distinguen gónadas y se miden clítoris, penes, para luego proceder a la intervención sobre ese cuerpo que no puede ser nombrado bajo la lógica binaria varón-mujer que nos gobierna.

Las intervenciones normalizadoras inmediatas son necesarias entonces, se argumenta, para sostener el legado experiencial de la especie, que autoriza y reconoce solo un repertorio limitado de identidades posibles, articuladas en vivencias de lo corporal que pertenecen, en nuestra experiencia, más a la cultura, a los psiquiatras y a los médicos, a los maestros y a los padres, antes que a las mismas

${ }^{7}$ Bromance (Brother [hermano] + romance) es un término cuya autoría suele atribuirse a Dave Carnie, editor de la revista Big Brother. Se refiere generalmente a fuertes vínculos de amistad entre skaters varones. La noción fue mutando y en la actualidad se utiliza para caracterizar intensas relaciones afectivas entre amigos varones que transitan por el espacio ambiguo — delimitado social y culturalmente- entre la homosexualidad y la homosociabilidad (Church). Para mayor información, ver Smiraglia. 
personas intersex, que excepto en contadas oportunidades nunca son consultadas en la modificación quirúrgica de sus genitales $-\mathrm{y}$ en muchos casos, de su identidad de género. (Cabral, "Pensar la intersexualidad, hoy" 136)

Esto último conlleva graves consecuencias, porque bajo esta lógica se niegan los derechos fundamentales de esas personas que, por no encajar plenamente en ninguno de los moldes definidos en nuestras sociedades, son tratados como meros cuerpos sin subjetividades. Es por ello que "lo importante es que puedan ejercer todos sus derechos, comenzando por el derecho a elegir" (Fisher Pfaeffle 32). El movimiento político de personas intersex encarna la demanda por el respeto a la autonomía: "Autonomía corporal. Autonomía de la decisión. Derecho a la identidad y a la memoria. No es una sociedad sin géneros la que se pretende, sino el reconocimiento de la libertad inalienable de las personas para decidir sobre sus cuerpos" (Cabral, "Pensar la intersexualidad, hoy" 139).

A través de los años, el discurso médico ha detentado el monopolio sobre la representación de esos cuerpos: los define, los ilustra, los "normaliza" (Cabral, "Diferencias ambiguas"). Sin embargo, dos películas estrenadas recientemente en la Argentina $-X X Y$ y El último verano de la boyita- en lugar de renunciar a la posibilidad de la representación de esos cuerpos, pusieron a los mismos como protagonistas, disputando así la imagen que de la intersexualidad ha construido el discurso médico.

\section{$X X Y:$ ¿Y si no hay nada que elegir?}

Basado en el cuento "Cinismo" de Sergio Bizzio, ${ }^{8} X X Y$ tiene como protagonista a Alex ${ }^{9}$ (Inés Efrón), adolescente de 15 años que nació con genitalidad intersex. Sus padres, Suli (Valeria Bertuccelli) y Kraken (Ricardo Darín), para proteger a Alex, deciden dejar Buenos Aires e instalarse en una cabaña en el balneario de Piriápolis, Uruguay. El conflicto se desata cuando llegan de visita Érika (Carolina Peleritti), una vieja amiga de Suli, Ramiro (Germán Palacios), su marido y Álvaro (Martín Piroyansky), su hijo adolescente. La visita tiene un motivo que se hace claro rápidamente: Suli invitó a Érika para que su marido, que es cirujano plástico, evalúe el caso de Alex y su posible intervención quirúrgica. Dos líneas sostienen la narración, por un lado el dilema que deben enfrentar los padres sobre la decisión en torno al cuerpo de Alex -intervenir, no intervenir, o dejar la decisión en las manos de su hijx $-{ }^{10} \mathrm{y}$, por otro lado, el romance que comienza entre Alex y Álvaro.

8 "Cinismo" es un cuento que forma parte de Chicos (2004). En este mismo volumen se encuentra "Un amor para toda la vida", llevado al cine por Paula Hernández bajo el título Un amor (2011).

${ }^{9}$ Alex es un nombre ambivalente utilizado tanto en varones como mujeres. En "Cinismo" el nombre que se le da a este personaje es Rocío. Meri Torras también llama la atención sobre este detalle.

${ }^{10}$ Según Margaret Frohlich, en esta línea narrativa "Suli and Kraken's parental decisions and doubts reflect contemporary ethical and medical issues related to intersexuality" [Las decisiones y dudas que como padres tienen Suli y Kraken reflejan los problemas éticos y médicos contemporáneos en relación a la intersexualidad] (161). Aunque su lectura es interesante, en este punto, debo distanciarme de la misma. Los debates actuales en torno a la intersexualidad no son - tanto o tan solo- en torno a qué hacer, intervenir o no - hormonal, quirúrgicamente- sobre el cuerpo, sino a quién le corresponde esa decisión. Por lo tanto, Suli y Kraken no 
Con respecto a las decisiones estéticas y narrativas, algo que resalta a primera vista es la construcción de una analogía entre el cuerpo de Alex y la animalidad (Trerotola; Frohlich; Torras). Un claro ejemplo es la secuencia inicial del film, que nos presenta a su protagonista a través de un montaje paralelo entre un plano del fondo del océano — con su flora y fauna marítima- y otro en donde Alex corre por el bosque. ${ }^{11}$ Un montaje cuyo ritmo se va acelerando, no solo a nivel visual, sino también sonoro, pasando del sonido hueco del océano, a la respiración jadeante de Alex mientras corre, finalizando con un grito mientras se precipita al suelo con un cuchillo. Luego los títulos " $X X Y$ ", en donde la $Y$ se muestra deliberadamente como una $X$ con una de sus patas cortada. Un cuerpo que no detenta un género reconocible y que por ello pareciera recorrer los límites de lo (no) humano. Un cuerpo que es protagonista, pero cuya "radical diferencia" se elude.

La primera información sobre Alex, sobre su cuerpo, la recibimos a través de la mirada de Álvaro; ${ }^{12}$ cuando sube al auto de su familia, nota el archivo sobre Alex - acompañado por una foto- que el padre está estudiando. Ramiro, al advertir la mirada de su hijo, esconde el archivo y cierra también el libro El origen del sexo cuyo autor es justamente Kraken. Algo se sugiere, y al mismo tiempo se esconde. El primer encuentro entre Ixs adolescentes será a través de un hueco en las maderas del piso de la entrada del hogar de la familia Kraken, desde donde Alex observa. ${ }^{13}$ Luego volvemos a

son los únicos que encarnan las posibles posiciones en este debate, sino que en el film justamente se intenta, a través del protagonismo que Alex va tomando, poner en dudas también si es a ellxs a los que le corresponde tomarla. Retomaré esta discusión en las conclusiones.

${ }^{11}$ Diego Trerotola llama la atención sobre este y otros ejemplos en el artículo citado. Asimismo, Margaret Frohlich también retoma esta secuencia inicial para abordar la posibilidad de agencia dentro del marco de la naturaleza. Para la autora "The film shows us again and again that Alex is at home in nature, and nature is in her, from the lizard that crawls up the terrain of her leg to the feather (s)he uses as a bookmark and the rain that falls when (s)he cries" [El film muestra una y otra vez que Alex están en su hogar en la naturaleza, y que la naturaleza está en ella, desde el renacuajo que trepa por su pierna hasta la pluma que usa como un señalador y la lluvia que cae mientras llora] ("What of unnatural bodies?" 163). Vinodh Venkatesh también se detiene sobre esta escena inicial y ofrece tres líneas de lectura posibles: el corte de la $x$ señalando la posible incisión que Ramiro podría realizar sobre el cuerpo de Alex; o la violenta fuerza descentrada que está en el núcleo de la película o —la más interesante y original- quizás promueve la idea de que Puenzo con ese corte está separando el film de toda una genealogía anterior que intentó hacer cine queer (New Maricon Cinema, Capítulo 6).

${ }^{12}$ En estas primeras escenas la mirada de Álvaro es muy relevante, y disputa el protagonismo de Alex. Esta indefinición inicial quizás se deba a una huella de "Cinismo" en la adaptación, en donde el protagonista es Álvaro, no Alex [Rocío]. Meri Torras propone otra línea de lectura "En ambos filmes el/la intersex es otrx, constituye la alteridad porque tanto $X X Y$ como El último verano de la boyita usan, con mayor o menos rigidez, el filtro de la mirada de otro personaje para dirigir la focalización [...]. El sujeto intersex sigue siendo poseedor de más o menos voz y/o agencia a través de los diálogos en los que participa y las acciones que emprende, pero no gobierna la mirada dominante del filme sino que más bien ésta se dirige sobre él/ella" ("Lo que no calla el cuerpo" 150).

${ }^{13}$ Frohlich sostiene que Alex "ocuppies a liminal position between her identity as daughter and intersex child that is to be kept hidden from public perception" [ocupa una posición ambigua entre su identidad como hija y como intersex que tiene que ocultarse de la mirada pública] (163). Una posición queer en el espacio doméstico, cercana, pero que no termina de formar parte del paradigma de la familia tradicional. Esta lec tura parece contradecirse con su posterior señalamiento sobre la circulación de Alex dentro de la casa, en relación con Álvaro, en donde domina el espacio visual. La asociación que realiza la autora entre el personaje de Alex 
portar la mirada de Álvaro y entramos a la casa. Un paneo sobre una mesa con fotos - que opera como una especie de biografía visual - que comienza con la imagen de lo que parece ser una niña sonriente, hasta llegar a la de una adolescente que con su mano intenta tapar la cámara, ya sin esa sonrisa. Durante todo el film se nos propone un juego en torno a la genitalidad de Alex, que como espectadores nunca vemos en forma directa, sino que está insinuada a través de diálogos, o dibujos y pertenencias delx protagonistx; como la muñeca que en su pecho lleva escrito el nombre "Alex", pero de la cual — por la puesta de cámara - se nos niega la posibilidad de ver qué tiene entre sus piernas. Una puesta en escena que insiste en mostrar que algo se oculta. ${ }^{14}$

De ahí en más las dos líneas de narración se disparan, y la interacción entre los distintos personajes comenzará a hacer tambalear la supuesta tranquilidad del balneario. Mientras los padres y las madres del film quedarán, en principio, atrapados en la primera línea (intervención o no sobre el cuerpo de Alex), Ixs chicxs abrirán paso a su propia línea narrativa, que no podrá escapar del todo de la primera -opera como atmósfera-, pero que construye sus propios ritmos, puntos de inflexión, tonos. Alex, luego de observarlo a la distancia, decide interceptar a Álvaro en la playa con una pregunta directa que marcará toda su relación: "¿Te hiciste la paja?... Yo nunca me acosté con nadie, ¿Te acostarías [conmigo]?". Álvaro siente incomodidad y al mismo tiempo una fuerte atracción que irá creciendo a medida que avance la película. Después de varias negativas por parte del adolescente, el encuentro sexual será desatado por un cambio en la actitud pasiva y expectante de Álvaro. Si hasta el momento vemos la relación de ellxs guiada por el ritmo impuesto por Alex, donde simplemente Álvaro observa y/o reacciona frente a sus acciones; ahora Álvaro pondrá en palabras lo que la primera línea de narración viene contando y rodeando (amenazando) esta historia: "Vos no sos normal, vos sos distinta y lo sabés. ¿Por qué te mira la gente así?". Esta intervención del afuera en el vínculo que estaban comenzando a solas, llevará a Alex a escapar hacia una especie de establo cercano a la casa, y es en ese mismo lugar donde Alex vuelve a tomar las riendas de la relación, besando y tocando a Álvaro, el cual, a pesar de sus anteriores negativas a través de las palabras (¿de otros?), corresponderá con su cuerpo.

Así pues, $X X Y$ no solo trata sobre la intersexualidad, sino que también es un relato sobre la iniciación sexual. La relación entre Álvaro y Alex constituye un encuentro que a pesar de sus luchas internas - los indicios que plantea la película en torno a la posible homosexualidad de Álvaro, y la indefinición de Alex no solo en relación a su género, sino también a su deseo-, habilita la

escondido debajo la casa, y su "identidad ambivalente" creo es problemática. Alex circula sin mayores dificultades dentro del espacio doméstico, aún con/y en relación a sus visitantes. Quizás en esta escena lo que podemos leer es el intento de Alex, frente a la llegada de un elemento extraño a su hogar, por mirar antes de ser miradx.

${ }^{14}$ Vinodh Venkatesh arriesga una hipótesis sobre esa decisión: "Not allowing the viewer to see, leaving her difference to the imagination [...] and therefore in the realm of unrepresentability, the film implic ates the viewer in the collective homosocial fetish of wanting to see her penis and her vagina" [Al no permitir a los espectadores ver, dejando su diferencia a la imaginación [...], por lo tanto en el campo de lo irrepresentable, el film involucra al espectador en el fetiche colectivo homosocial de querer ver su pene y vagina] (Capítulo 6). Más adelante agrega que solo "veremos" (sentiremos) esa diferencia oculta en el momento en que Alex penetre a Álvaro. 
posibilidad del cuerpo como goce más allá de cualquier definición identitaria. Por lo menos hasta que la mirada de Kraken interrumpe el acto sexual, es decir, hasta la irrupción de la mirada de un otro. Porque al mismo tiempo que se construye la posibilidad del placer $-\mathrm{y}$ por qué no del amorse construye la del peligro. Alex no solo tendrá que lidiar con el trauma inicial que le provoca el verse en la mirada de su padre mientras penetra a Álvaro, sino también con la violencia ejercida por una horda de chicos del lugar, que luego Ix perseguirán como a una presa, con el fin de ver precisamente aquello que el film nos niega. Es por ello que una doble decisión quedará en las manos de Alex: no solo la de intervenir o no sobre su cuerpo para la adecuación del mismo a alguno de los dos modelos corporales hegemónicos, sino también la de denunciar o no a sus atacantes. La primera decisión es la de dejar que las cosas sigan "su curso" sin intervención de la medicina - "iy si no hay nada que elegir?", se pregunta Alex-. Y la decisión de denunciar a sus atacantes, que tendrá como inevitable consecuencia - consecuencia que no queda plasmada dentro del texto fílmico, sino anunciada por su padre- hacer pública su condición de persona intersex. $^{15}$

A pesar y más allá de las figuras alegóricas —zanahorias y jamones que se cortan, tortugas hembras y machos, entre tantas otras $-{ }^{16} X X Y$ cuenta una historia: "no relata un diagnóstico [...] no pide solidaridad, no ofrece piedad, no dice qué pasa, no dice qué hacer" (Cabral, "No saber Acerca de $X X Y " 107)$. Sin embargo, hacia el final de la película se produce un giro testimonial a través de la incorporación de otro personaje, Juan Scherer. Juan nació con ambigüedad genital y sufrió cinco intervenciones quirúrgicas durante sus primeros años de vida para adaptar su cuerpo al de una mujer, proceso que luego decidió revertir para convertirse en varón. Su historia irrumpe en el film con fines exclusivamente explicativos — para Ixs espectadorxs - y redentorios — para Kraken, el padre que frente a todo lo sucedido en los últimos días siente que su certeza en torno a lo no intervención quirúrgica sobre el cuerpo de su hijx comienza a tambalear. Será Scherer el que finalmente le devuelva algo de paz a Kraken: "si la operaban hubieran hecho que tenga miedo de su propio cuerpo, y eso es lo peor que se le puede hacer a un hijo". Este momento es importante ya que hacia el final del film descubrimos $-\mathrm{y}$ no de forma inocente en una charla con Ramiro, el cirujano- que fue él quien convenció a Suli de no intervenir el cuerpo de Alex, por lo menos no quirúrgicamente; ya que al comienzo del film nos enteramos de que Alex está bajo tratamiento

${ }^{15}$ Aunque en el balneario ya está instalada la sospecha. Al comienzo de la película se nos brindan pistas de que la pelea de Alex con su mejor amigo Vando (Luciano Nóbile) se produce porque su amigo no supo guardar el secreto.

${ }^{16}$ Con respecto a estas imágenes, Diego Trerotola advierte: "Aunque parezca paradójico, XXY respalda aberrantemente el falocentrismo a partir de la simplificación exacerbada del conflicto central: 'la castración', repetido literal y metafóricamente" (369). Por su parte, Margaret Frohlich presenta una distinción entre estas imágenes "In spite of their differences, both of these first representations of cutting (Alex with the machete and Kraken with the sea turtle) function as descriptions, rather than alterations, of biological sex. They stand in contrast to acts of cutting performed by those characters who are most clearly interested in surgically altering Alex's body". [A pesar de sus diferencias, esas dos primeras representaciones de cortes (Alex con el machete y Kraken con la tortuga) funcionan como descripciones, no alteraciones sobre el sexo biológico. Irrumpen en contraste con los cortes realizados por aquellos personajes que claramente están más interesados en alterar quirúrgicamente el cuerpo de Alex] (165). 
hormonal, proceso que pareciera empezar a abandonar al tirar una de sus pastillas. El mensaje es claro para quien quiera escucharlo: "normalización" = castración.

Al cerrar esa primera línea narrativa, en donde hasta la madre de Alex, Suli, gestora de la invitación al cirujano, comienza a entender este mensaje, la segunda línea vuelve a ser retomada para dar pie a su desenlace. En la última secuencia, cuando los padres de Álvaro deciden volver a su casa, al llegar al muelle, Álvaro va en busca de Alex y, cerca del río, quedan a solas. Alex confiesa su amor. Y cuando Álvaro confiesa el suyo, Alex interrumpe dudosx su declaración: "A vos te pasó otra cosa [...] ¿Qué te da más lástima no verme más o no haberla visto [la pija]?". En ese momento, frente a esta última prueba de amor, y mientras Alex se abre el pantalón fuera de plano, Álvaro en silencio, intentando mantener sus ojos inundados de lágrimas en los de Alex, fracasa y vuelve su mirada sobre lo que justamente la película nos niega. ${ }^{17}$ En la última escena, Alex, su madre y su padre caminan por el muelle hacia el auto para volver a su casa. Una doble vuelta, entonces, la de la familia de Álvaro hacia Buenos Aires, y la de la familia de Alex hacia su hogar. Pero una vuelta que no es circular, porque no se puede regresar a lo que ya no existe.

\section{El último verano de la boyita o sobre el fin de la infancia}

El último verano de la boyita comparte con $X X Y$ el abordaje de la intersexualidad, sin embargo, el film se centra principalmente en el pasaje de la infancia a la adolescencia y el despertar sexual en su doble faceta: de confusión, pero también de curiosidad. De nuevo, al igual que en $X X Y$, los títulos iniciales son altamente descriptivos y brindan ciertos indicios de la atmósfera que rodeará el film. Sobre un fondo negro, los créditos del equipo técnico y creativo se insertan sobre figuras gráficas en donde lo humano, lo animal y lo mecánico parecieran mezclarse, confundirse. Figuras de caballos y su genitalidad explicada a través de sus copetes, una sucesión de imágenes de cuerpos femeninos en el transcurso del tiempo, un primer plano del órgano genital femenino descripto en términos médicos, y diagramas de lo que al final sabremos es una boyita —una casa roda-flotante- con el título del film inscripto en la figura final.

La historia se inicia durante un verano en la ciudad de Rosario, Argentina; la referencia a Ronald Reagan permite inferir que la acción se desarrolla en los años ochenta. Jorgelina (Guadalupe Alonso), se ve obligada a lidiar con la entrada a la adolescencia de su hermana mayor, ${ }^{18}$ Luciana (María Clara Merendino), quien comienza a redefinir los espacios del hogar buscando privacidad a través de un cuarto propio, o de su negación a compartir el baño con su hermana menor. Por

${ }^{17}$ Frohlich propone una lectura distinta en torno esta escena "In a gesture that both empowers her as the one who allows others to see her body and conforms to the expectation that this gaze trumps all other desires, she pulls down her pants" [En un gesto que no solo la empodera como la que permite a otros ver su cuerpo y que se ajusta a la expectativa de que la mirada triunfa sobre todos los demás deseos, ella se baja los pantalones] (167).

${ }^{18}$ Meri Torras también hace hincapié sobre este dato "Jorgelina [...] es una nena inquieta, con personalidad, que pasa por un sentimiento de pérdida de su hermana Luciana desde que a ésta le vino la menstruación e ingresó de pleno en el mundo de la adolescencia" (152). 
ello, frente a la opción de pasar sus vacaciones en Villa Gessell sintiéndose excluida por Luciana, en lugar de irse con su mamá (Sylvia Tavcar), Jorgelina decide viajar al campo con su padre (Gabo Correa), en donde pasará sus días con Mario (Nicolás Treise), el hijo de los peones. Una mancha de sangre en la montura de un caballo y otra en el pantalón de Mario, darán inicio a un camino de descubrimiento conjunto.

Previo a la presentación del personaje de Jorgelina, acaso lo interesante es la decisión de dedicar el primer minuto de la secuencia inicial del film a Mario. La escena comienza con Mario acariciando a un caballo. El tono íntimo y cercano de esa primera imagen va a ser interrumpido por el ingreso de su padre y dos peones que con sogas intentarán adiestrar al animal. Bajo la dirección del padre, Mario se vuelve parte del proceso, no solo como testigo sino como partícipe. Cuando logran domarlo y tirarlo al piso, Mario vuelve a poner sus manos sobre él repitiendo el gesto íntimo, aunque ahora más cercano a la piedad que al cariño. El caballo logra levantarse y le dedica su última mirada a Mario, ese gesto de libertad queda obstruido cuando en plano general vemos que el caballo ya se encuentra atado y conducido por los peones. Esta escena no nos dice solo algo sobre Mario, sino que sintetiza en pocas imágenes la etapa en que se encuentra también Jorgelina: la pubertad, Mario en el borde final, Jorgelina en el inicial. ${ }^{19}$

La elección de contar esta historia desde el punto de vista de Jorgelina nos permite transitar esta experiencia con una mirada libre de los prejuicios y las convenciones sociales del mundo de los adultos, abriendo la posibilidad a un vínculo amoroso entre estos dos personajes. Un revisitar nostálgico sobre el final de la infancia, sobre el fin de un espacio y tiempo en el cual aún es posible escapar de la rigidez de los roles de género y sexuales hegemónicos, sin que ello conlleve necesariamente una sanción. ${ }^{20}$ Ya no niña, pero tampoco una mujer todavía; Jorgelina está cambiando, y el mundo que la rodea (la) está cambiando (a ella). Ese momento en que comenzamos a explorar nuestros cuerpos sin el objetivo de explicarlo sino de experimentarlo, se ve constantemente intervenido, dirigido, por los otros: Peca (Edith Nadalin), la señora que trabaja en la casa, la alecciona a través del miedo sobre los peligros de meterse el dedo a través de la "bombachita"; su hermana marca distancia emocional y espacial; los libros de medicina tirados por la casa ilustran la "evolución" del cuerpo femenino, etc. Debido a esa sensación de extranjera dentro de su comunidad de mujeres, opta por el alejamiento "real": irse con su padre —al cual aún no conocimos- al campo.

${ }^{19}$ Vinodh Venkatesh propone una lectura en torno a esta escena, en relación con otras del inicio del film en donde vemos a Mario aprendiendo las tareas del "gaucho", como el modo de inserción de su cuerpo dentro de la masculinidad hegemónica (Capítulo 5). Proceso que se verá interrumpido hacia el final, cuando el padre decide expulsarlo hacia el mundo de las tareas femeninas con su madre.

${ }^{20}$ Torras presenta una lectura distinta: "Tanto el post-adolescente Álvaro, en XXY como la pre-adolescente Jorgelina, en El último verano de la boyita, son seres que forcejean con los procesos de sujeción-subjetivación que les atenazan a la sociedad" (152). Aunque en el caso de Álvaro sin lugar a dudas esto es cierto; no creo —como lo detallo en el artículo— que se dé la misma dinámica en el caso de Jorgelina. 
El primer encuentro entre Jorgelina y Mario está signado por el anuncio de peligro. Un perro entra a la casa con un pájaro muerto en su hocico. Jorgelina se asusta y al ver a Mario cerca le pide por favor que lo saque. A través de esta escena nos damos cuenta de que ellxs se conocen desde antes, aunque algo parece haber cambiado. Mario es unos años mayor, como Luciana, y se muestra distante frente a la propuesta de ir al tajamar. La invitación de nadar con ella se repite durante la película, como la declinación de Mario con la excusa de que tiene que trabajar. Jorgelina va a buscarlo al establo, donde descubre que también él, ahora, tiene "cuarto propio". Toman dos caballos y salen a cabalgar. Mientras charlan surge el tema de Luciana y Jorgelina confiesa que fue mejor no haber viajado con ella, ya que su hermana está insoportable desde "que le vino [la menstruación]". Mario parece desconocer precisamente lo que le está sucediendo a su cuerpo. De nuevo, al borde del agua, Jorgelina repite su invitación, y a pesar del notorio calor que invade el cuerpo de Mario, él vuelve a negarse, es más, se frena unos metros antes de llegar, como si fuera un borde que no puede traspasar; a diferencia de Jorgelina, que como una boyita circula por tierra y agua, y se mueve por los distintos espacios, sin puertas o permisos.

Aunque al igual que en $X X Y$ la ambigüedad del cuerpo de Mario es sugerida a partir de indicios que se van develando - como la faja que usa en su pecho o la mancha de sangre-esa ambigüedad no tiene un peso visual y narrativo equivalente. Podríamos arriesgar que esto se debe a que ni Mario, ni sus padres —Elba (Mirella Pascual) y Oscar (Arnoldo Treise)— pueden (o quieren) terminar de decodificar ese cuerpo. Así pues, El último verano de la boyita añade una capa más de lectura que no se encuentra desarrollada del todo en $X X Y$ : el de las desigualdades sociales y/o culturales, y su relación con las posibles aproximaciones a la diversidad, sus distintas estrategias y tecnologías. En un diálogo entre Jorgelina y su padre, se condensa el —en palabras de bell hookssobrecruzamiento de opresiones: las normas de género dominantes y las normas que rigen los distintos espacios socio-culturales:

Jorgelina: Vamos a ir a la carrera, ¿no?

Padre: Claro, es muy importante para Mario y su familia... es probarse como hombre.

Jorgelina: ¿Por qué tiene que probar?, ¿por si no le gusta?

Padre: No, digo probarse... tiene que demostrar que es un hombre.

Jorgelina: ¿Cómo lo va a demostrar?

Padre: Y así... acá es así.

La mancha de sangre en la montura de Mario disparará un camino de descubrimiento — tardío, en su caso- en conjunto. Jorgelina lo motiva a interrogarse, y al compararse con un libro de biología Mario llega a la conclusión de que no es "normal". Jorgelina, con la mente de una niña que recién comienza su camino a la adolescencia, sin haber atravesado aún la etapa en donde las normas de género terminan de reclamar sus cuerpos, declara no ser muy normal tampoco y que le gusta Mario "así". La intersexualidad sigue sin ser nombrada hasta que el padre de Jorgelina, doctor, lo revisa. En una charla con la madre de Mario, Elba, descubrimos que en el nacimiento su hijx le 
explicaron que "le crecería [el pene]" y si seguía igual que fuera a Paraná por unos estudios, pero como era "sanito" no se quisieron preocupar. Pero unos estudios guardados por ella del primer sangrado nos revelan la situación de Mario. Cuando el padre intenta explicarle en lenguaje médico a Jorgelina la situación de su amigx, ella se tapa sus oídos y solo escuchamos ruido. De nuevo la pregunta irrumpe: ¿Cómo lidiar con la diferencia? Pareciera, a través de esta escena, que se trata de una pregunta de los otros, porque para Jorgelina la diferencia aún no termina de ser construida, comprendida. Algo que solo aprenderá al presenciar la golpiza que el padre de Mario le da a su hijx.

Producto de la impotencia del padre de Mario para lidiar con esta nueva información, la furia se desata sobre su cuerpo, sobre ese cuerpo que ya no puede ser nombrado. Y como su "hijo" ya no puede demostrar que es "un hombre" en la carrera, decide vender su caballo. Mario escapará, pero solo para juntar la fuerza necesaria y volver el día de la competencia, arrebatada por su padre, para tomar por asalto a su caballo, Yayo. Quizás, ya no para probar que es un hombre, sino para demostrar que simplemente es. ${ }^{21}$ Una prueba distinta que, por ello, no termina con Mario recibiendo un premio o la aprobación de sus pares, sino cabalgando lejos de ahí. Ahora Mario, al igual que Jorgelina, comienza a traspasar las fronteras que delimitaban los espacios que podía o no transitar, redefine su geografía, concluyendo su recorrido en el agua, Ixs dos nadando juntxs. ${ }^{22}$

El viaje —no solo espacial, territorial - de la protagonista, culminará con su llegada a Villa Gesel, en donde finalmente se encontrará con su mamá y su hermana. Pero Jorgelina ya no es la misma. La cámara se detiene en ella, mientras, de fondo, escuchamos que la madre habla con una amiga sobre la experiencia de su hija, y de un posible tratamiento terapéutico. Ellas nombran, analizan, etiquetan; pero no Jorgelina, que al escuchar decide levantarse de la arena. La cámara abre el plano para incluir a la madre y a su amiga, y al interpelarla primero con el nombre de "Jorgi", y después "Jorge", ella aclara con fuerza "Jorgelina". A continuación, vemos un plano de la niña en la orilla del mar con una malla de dos piezas — durante el film siempre la vimos con una entera-, ya no corriendo hacia y zambulléndose en él, sino en el borde, rodeada por la hermana y sus amigos. En un diálogo final con la hermana, al ser interrogada sobre lo sucedido en el campo, Jorgelina responde que "es un asunto privado", dando así comienzo no solo al final de la película, sino también de la infancia.

${ }^{21}$ Para Torras, que Mario monte a Yayo en la carrera "es el rito de afirmación no sólo de su libertad sino, como advierte el padre de Jorgelina, de su hombría: Mario demuestra que es un hombre" (157). En este punto, me acerco más a la lectura presentada por Vinodh Venkatesh; coincido en que en esta escena se despliega su posibilidad de agencia, tal cual señala Torras. Sin embargo, no creo venga necesariamente acompañada de una demostración de que es un "varón", o a lo sumo, lo importante en esta escena es que al probar que es "varón" y luego huir de la aprobación de sus pares, pone en crisis el paradigma masculino mismo.

22 Señala Torras: "Jorgelina irá con él/ella de nuevo al río, en el que Mario nunca se bañaba para no mostrar sus pechos incipientes a su nueva amiga, pero esta vez sí, ella desenvolverá su cuerpo como un regalo y se bañarán juntxs" (160). También es interesante el análisis propuesto por Vinodh Venkatesh, quien señala que al meterse en el río, el mismo río donde Mario no quería bañarse porque "la naturaleza es traicionera", permite a esa "naturaleza" desplegarse (Capítulo 5). 


\section{A modo de reflexión final}

En los últimos años, se han arriesgado distintas lecturas sobre estos films en relación al debate en torno a la intersexualidad. Una de las hipótesis de Margaret Frohlich es que, en el caso de $X X Y$, "más que argumentar a favor de cualquier opción que los personajes adolescentes puedan llegar a hacer respecto a sus cuerpos o sexualidades, $X X Y$ en última instancia prioriza la naturaleza sobre la agencia: la decisión correcta es la decisión natural" (161). ${ }^{23}$ Es justamente esta posible línea de lectura la que preocupa a Meri Torras en ambas películas. Para la investigadora, son dos líneas las que se abren: por un lado, la elección de no intervenir el cuerpo hormonal o quirúrgicamente puede interpretarse como forma de "resistencia al sistema binario de género" (160), alternativa que Torras suscribe; pero por el otro, en cambio, surge la posibilidad de que esta elección sea interpretada, como hace Frohlich en el caso de XXY, como una "no elección".

Frente a estas líneas de lectura contrapuestas, concuerdo con la clara - y preocupante- distinción que señala Torras en su trabajo; aunque coincido sobre todo en los riesgos que implicaría la segunda línea de lectura, y no tanto en su posibilidad. En el caso de $X X Y$ no solo se despliegan argumentaciones —implícitas o explícitas - sobre qué decidir: intervenir o no sobre el cuerpo, la sexualidad; sino que el dilema que se convierte en central es quién es el sujeto que debe tomar esa decisión. La pregunta/respuesta de Alex - "y si no hay nada que elegir" - no resuena tanto como un triunfo de la naturaleza por sobre la agencia: lo relevante de esa declaración — de la elecciónno es el contenido de la misma, sino su sola enunciación.

Por otro lado, en el caso de El último verano de la boyita, y a diferencia de $X X Y$, las argumentaciones en torno al debate sobre la intersexualidad se encuentran ausentes en el relato o, por lo menos, no juegan un papel central. El foco no está puesto tanto sobre las posibles elecciones o quién debe tomarlas, sino sobre las desigualdades etarias, sociales y/o culturales, y su relación con las posibles aproximaciones a la diversidad, según el caso. El eje no es tanto la elección —qué hacer y quién debe hacerlo—, sino su posibilidad o no, y las consecuencias de llevarla a cabo frente a las normas hegemónicas de género y sexuales que rigen en nuestras sociedades; y es a través del tránsito de la niñez a la pubertad que encarna Jorgelina que experimentamos su fuerza desatada.

Por otro lado, que películas como $X X Y$ y El último verano de la boyita comiencen a circular probablemente no solucionará los prejuicios en torno al cuerpo intersex, ni romperá el monopolio que sobre esos cuerpos detentan la medicina o la psiquiatría. Es más, ninguno de ellas escapa al discurso médico, encarnado no solo en personajes como el cirujano plástico ${ }^{24}$ en $X X Y$ o el padre

23 "Rather than arguing in favor of any choice that the adolescent characters might make in regard to their bodies and sexualities, XXY ultimately prioritizes nature over agency; the right choice is the natural choice".

${ }^{24}$ A diferencia de "Cinismo" en donde Kraken es un sociólogo y Ramiro un músico de cine, en $X X Y$ el padre de Alex es un biólogo marino que pronuncia la primera y bastante significativa palabra del film mientras examina una tortuga marina: "hembra"; y el padre de Álvaro es un cirujano plástico que según la caracterización de su hijo "corrige deformidades". Ya la misma frase que acompaña al título de la película está teñida del mismo: "el sexo nos hace hombres y mujeres, o las dos cosas". 
médico de Jorgelina en El último verano de la boyita, sino también en los libros de medicina en los que Alex, Jorgelina y Mario se interrogan. Sin embargo, la ciencia ya no representa la única opción de lectura posible, sino solo una de ellas. Por otra parte, las emociones que provoca la "diferencia" suelen oscilar entre la condena, la vergüenza, la curiosidad, el deseo y la aceptación. Acaso lo interesante de estos films es que nos proponen un viaje que recorre cada uno de estos posibles caminos; participando, de esta manera, del desafío al que llama Teresa de Lauretis de producir otra mirada, de construir las condiciones para la representación de otros sujetos de la mirada. Pareciera que estos films no pretenden tanto mostrar "la realidad" de los cuerpos intersex, o revelar una especie de "verdad" oculta, sino justamente desarticular, a través de distintos procedimientos narrativos y/o figurativos, la posibilidad de una —única e indiscutible- verdad sobre los mismos. Retomando una reflexión de Mauro Cabral ("No saber - acerca de XXY"): este mundo no es distinto porque a partir de estas películas se sepa más sobre la intersexualidad, sino que es distinto porque, gracias a ellas, comienza a saberse un poco menos.

Para finalizar, me gustaría retomar - y ampliar - una reflexión de Vinodh Venkatesh. En su libro New Maricon Cinema, el autor propone una relación entre la conversión de Álvaro en "raro" a través de su comportamiento, que lo enfrenta a la masculinidad hegemónica que encarna su padre, y la rareza de Alex por su diferencia orgánica. En realidad, la tensión entre "raro" y "normal" opera como una espada de Damocles en ambos films. Los cuatro personajes principales -Jorgelina, Mario, Alex y Álvaro- más tarde o más temprano, se sentirán interpeladxs por las normas de género y sexuales hegemónicas que exigen una definición. Por poseer un cuerpo que no encuadra en el modelo femenino o masculino, o por experimentar un deseo que no coincide con lo que se espera de ellxs, por tener un cuerpo que sí lo hace, o simplemente por no comprender aún del todo qué significa la "normalidad". Y ellxs lo saben: "Vos no sos normal, vos sos distinta" le dice Álvaro a Alex, una acusación que pareciera tener dos direcciones, dos destinatarixs; "Yo no soy normal" declara Mario, a lo que Jorgelina contesta: "Yo tampoco soy muy normal".

Lo interesante quizás, es que a pesar del sentimiento de opresión presente en ambas películas, ese no sea es el eje principal de las mismas o, por lo menos, no clausure la posibilidad del encuentro amoroso, amistoso, sexual- entre los personajes. A diferencia de las imágenes estáticas y definidas de los libros de medicina que se cuelan en los planos, cada uno de estos personajes circula produciendo fisuras: en la trama, en los otros y en ellxs mismos. Aquí radica, creo, la posibilidad de pensar estos films en diálogo con el Nuevo Cine Queer, ya que se detienen sobre "preguntas queer, no respuestas queer" (Rich 180). Dos propuestas distintas que no intentan ofrecer otra mirada piadosa y cerrada sobre "Ixs otrxs", en disputa con la hegemónica; son, más bien, invitaciones a expandir el orden de lo "posible", echando luz no sobre lo que debemos hacer, sino sobre la posibilidad de hacer. 


\section{Referencias bibliográficas}

Aaron, Michele. "New Queer Cinema: An Introduction". New Queer Cinema: A Critical Reader. Ed. Michele Aaron. New Brunswick-New Jersey: Rutgers UP, 2004. 3-14. Impreso.

Aguilar, Gonzalo. Otros mundos. Un ensayo sobre el nuevo cine argentino. Buenos Aires: Santiago Arcos, 2006. Impreso.

Amado, Ana. "Cine Argentino. Cuando todo es margen". Pensamiento de los Confines 11 (2002): 8794. Impreso.

Bizzio, Sergio. "Cinismo". Chicos. Buenos Aires: Interzona. 7-33. Impreso.

Butler, Judith. El género en disputa. El feminismo y la subversión de la identidad. Trad. M. ${ }^{a}$ Antonia Muñoz. México: Paidós, 2001.

. Cuerpos que importan. Sobre los límites materiales y discursivos del "sexo". Trad. Alcira Bixio. Buenos Aires: Paidós, 2005. Impreso.

Deshacer el género. Trad. Patricia Soley-Beltrán. Barcelona: Paidós, 2006. Impreso.

Cabral, Mauro. "Diferencias ambiguas". Suplemento Soy de Página 12. 2009. Web. 21 nov. 2016 <https://goo.gl/TmB1eS>.

"No saber - acerca de XXY". Interdicciones. Escrituras de la intersexualidad en castellano. Ed. Mauro Cabral. Córdoba: Anarrés, 2009. 105-9. Impreso.

. "Pensar la intersexualidad hoy". Sexualidades migrantes. Género y transgénero. Ed. Diana Maffía. Buenos Aires: Feminaria, 2003. 131-42. Impreso.

Church, David. "'Propane Is for Pussies': Bellflowers's Bromance of Retro Technology and Hip Masculinity". Jum Cut. A Review of Contemporary Media 55 (2013): s. pág. Web. 20 feb. $2017<$ https://goo.gl/djyoVV>.

Colaizzi, Giulia. La construcción del imaginario socio-sexual. Valencia: Episteme, 1993. Impreso.

------. Género y representación: Postestructuralismo y crisis de la modernidad, Madrid: Biblioteca Nueva, 2006. Impreso.

Deleuze, Gilles y Félix Guattari. Mil Mesetas: Capitalismo y esquizofrenia. Trad. José Vázquez Pérez. Valencia: Pre-Textos, 1994. Impreso.

Fischer Pfaeffle, Amalia E. "Devenires, cuerpos sin órganos, lógica difura e intersexuales".

Sexualidades migrantes. Género y transgénero. Ed. Diana Maffía. Buenos Aires: Feminaria, 2003. 13-35. Impreso.

Foucault, Michel. Historia de la sexualidad I. La voluntad del saber. Trad. Ulises Guiñazú. Buenos Aires: Siglo XXI, 2008. Impreso.

-------. Tecnologías del yo y otros textos afines. Trad. Mercedes Allendesalazar. Barcelona: Paidós, 1995. Impreso.

Frohlich, Margaret. "What of Unnatural Bodies? The Discourse of Nature in Lucía Puenzo's XXY and El niño pez/The Fish Child". Studies in Hispanic Cinemas 8.2 (2011): 159-174. Impreso.

Haraway, Donna. Ciencia, cyborgs y mujeres. La reinvención de la naturaleza. Trad. Manuel Talens. Madrid: Cátedra, 1991. Impreso. 
"La promesa de los monstruos: Una política regeneradora para otros inapropiados/bles". Política y Sociedad 30 (1999): 121-63. Impreso.

Hiller, Renata y Daniel Jones. "A 6 años del matrimonio igualitario". Bordes. Revista de Política, Derecho y Sociedad. 15 jul. 2016. Web. 20 feb. 2017 <https://goo.gl/FKDhAp>.

Johnston, Claire. "Women's Cinema as Counter-Cinema." Feminism \& Film. Ed. E. Ann Kaplan. New York: Oxford UP, 2000. 22-33. Impreso.

Kristeva, Julia. Poderes de la perversión. Trad. Nicolás Rosa y Viviana Ackerman. Buenos Aires, Siglo Veintiuno, 1998. Impreso.

Lauretis, Teresa de. "Rethinking Women's Cinema". Figures of Resistance. Essays in Feminist Theory. Ed. Patricia White. Urbana-Chicago: U of Illinois P, 2007. 25-47. Impreso.

Technologies of Gender. Essays on Theory, Film and Fiction. Bloomington: Indiana UP, 1996. Impreso.

Lykke, Nina y Rosi Braidotti, eds. Between Monsters, Goddesses and Cyborgs: Feminist Confrontations with Science, Medicine and Cyberspace. London: Zed Books, 1996. Impreso.

Maffía, Diana, comp. Sexualidades migrantes. Género y transgénero. Buenos Aires: Feminaria, 2009. Impreso.

Parmar, Pratibha. "Queer questions: a response to B. Ruby Rich". Women and Film: A Sight and Sound Reader. Eds. Pam Cook y Phillip Dodd. Philadelphia: Temple UP, 1993. 174-75. Impreso.

"The moment of Emergence". Queer Looks. Perspectives on Lesbian and Gay Film and Video. Eds. Martha Gever, John Greyson y Pratibha Parmar. New York: Routledge, 1993. 3-11. Impreso.

Peña, Fernando Martín, ed. Generaciones 60/90. Cine argentino independiente. Buenos Aires: Fundación Eduardo Constantini, 2003. Impreso.

Preciado, Beatriz. "Queer: historia de una palabra". Parole de queer. 24 abril 2012. Web. 20 mayo 2017 <https://goo.gl/tXItjx>.

Testo Yonqui. Madrid, Espasa Calpe, 2008. Impreso.

Rich, Ruby. New Queer Cinema. The Director's Cut. Durham-London: Duke UP, 2013. Impreso.

Smiraglia, Romina. "Nuevas formas de la homosociabilidad en el cine argentino contemporáneo: el bromance como estrategia en Excursiones (de Ezequiel Acuña)". Imagofagia. Revista de la Asociación Argentina de Estudios de Cine y Audiovisual 11 (2015). Web. 20 abril 2016 <https://goo.gl/4GQzBP>.

Torras, Meri. "Lo que no calla el cuerpo. Mirada, norma y diégesis en XXY y en El último verano de la boyita". De cierta manera: cine y género en América Latina. Eds. Laurence H. Mullaly y Michèle Soriano. Paris: L'Harmattan, 2014. 149-61. Impreso.

Trerotola, Diego. "¡Ay!, metáforas punzantes. XXY: la diferencia entre el cine y la literatura". Otras historias de amor. Gays, lesbianas y travestis en el cine argentino. Comp. Adrián Melo. Buenos Aires: Ediciones Lea, 2008. 363-70. Impreso.

Venkatesh Vinodh. New Maricon Cinema. Outing Latin American Film. Austin: U of Texas P, 2016. Versión electrónica. 


\section{Filmografía citada}

XXY, Lucía Puenzo, 2007. Buenos Aires: Historias Cinematográficas Cinemanía, Wanda Visión S. A. y Pyramide Films.

El ultimo verano de la boyita, Julia Somolonoff, 2009. Buenos Aires: Travesia Productions, Domenica Films, El Deseo y Epicentre Films. 